\title{
Foundation Program English Language Learner Profile: A Case Study in Oman
}

\author{
Meenalochana Inguva \\ Sultan Qaboos University, Muscat, Oman \\ Victoria Tuzlukova \\ Sultan Qaboos University, Muscat, Oman \\ Pooja Sancheti \\ Sultan Qaboos University, Muscat, Oman
}

\begin{abstract}
This paper addresses the concept of the foundation program English language learner profile, its meaning and utility, and explores contextual variables that might have caused success or failure of the students enrolled in the foundation English language courses in tertiary education institutions in Oman. In more detail, it reports on the findings of the study that focuses on foundation English language program context-specific internal and external factors to highlight a variety of learner profile attributes shaping students' personality and equip them with 21 st century skills. A bilingual questionnaire in English and Arabic is used to provide detailed descriptions of the leaner profile, discuss experiences, achievements and challenges of the students of the foundation program exit level English language courses at the Centre for Preparatory Studies at Sultan Qaboos University. The results demonstrate that the analysis of the learner profile attributes can serve as a guide for informing future decisions about the foundation program English language curriculum design and implementation to enhance students' academic success.
\end{abstract}

Index Terms - learner profile, English language courses, foundation program students, skills, Oman

\section{INTRODUCTION}

In the 21st century, the demands of the learners and other stakeholders are becoming more powerful, and to align with this new scenario, numerous changes are taking place in language education in terms of teaching, learning, materials and methods of instruction. Some of these changes are shifting from the 'jug and mug' concept to the 'kindling thought' concept, from textbooks driven teaching to research based teaching, and from time-bound teaching to outcomes-based approaches. Teaching is centered around learning processes. Students need to acquire different skills to meet the stiff market competition for which today's learners must own responsibility of their learning. The biggest challenge that both teachers and students face today is coping with technological explosion and its interface in teaching and learning. These changes have created an awareness of the necessity to change and improve the preparation of students for productive functioning in the incessantly changing and highly demanding environment (Bar-Yam et al., 2002). In facing this challenge, it is necessary to consider the complexity of the language education system itself, the multitude of problems that arise out of this complexity and their redressal. One of the key issues to focus on and which plays a vital role in meeting the 21 st century demands is, learners' profile.

Learning is a highly complex activity and each learner is unique. Every student conceptualizes learning differently. Learner profile is a public statement of the desired student outcomes arising from common values and vision about the nature and purpose of education. These attributes are generally identified by key stakeholders and educators because these descriptors are instrumental in policy making and practice. Students must become self-directed learners, flexible and critical in their thinking because of the globalization and technological advancements. Educational administrators have focused more on learning environments, establishing more problem-based, collaborative and student-centered classrooms to represent the complex learning situations learners may face in a real- life work environment (Waterman, 1997).

This paper mainly focuses on the concept of learner profile, its meaning and utility. It reports on a study undertaken by the authors to explore the situational context responsible for the successful implementation of the English language component of the foundation program in tertiary education institutions in Oman. In this on-going study, one of the important areas was foundation program students' preconceptions, views and perceptions which form the first part of the paper. The second part details the study, the primary findings of the learner profile, student perceptions and how their responses express their attributes. The paper ends with reiterating the need for learner profiles, their role in the process of learning and accordingly, making pedagogical changes to suit the requirements of the 21 st century teaching and learning. 


\section{BRIEF LITERATURE REVIEW ON LEARNER PROFILES}

Literature on learning and learner profiles states that the three important aspects of learning that need to be considered in developing learner profile are cognitive aspects, conative aspects and affective aspects (Bullock, n.d.).

The cognitive aspect explores the psychological changes that take place as learners attain and understand new materials and ideas. According to Eisner (2000), Bloom made his taxonomy as a system for evaluation and assessment, and additionally, a down to earth apparatus for creating higher mental procedures and guidance for sequencing. He further says, that the peculiarity of scientific categorization lies in its hierarchical order. Each level of scholarly movement is subject to the one(s) beneath and is required for the one(s) above. To work at the Bloom's (2001) highest intellectual categorization - 'creation', a student will need vital learning, skills to comprehend, investigate and combine knowledge to create something new, resulting in self-development and the growth $\mathrm{t} / \mathrm{development}$ of the nation. Ausubel and Robinson (1969) argue that the most important factor influencing meaningful learning was not the child's stage of development, but the quality, clarity and organization of his or her present knowledge. According to them, new knowledge that cannot be adapted into the framework of the individual cognitive structure is 'rote'. Student success in learning depends on various factors. One of these factors is the effect of learning styles. Learning style includes preferred ways of learning in terms of absorbing, managing, and processing information, which is obtained either by remembering, reasoning, and/or problem solving. The studies by Schön (1991) and Boud, Cohen and Walker (1993) demonstrate that often reflecting on changing concepts is the key to effective learning. Heffler (2001) contends that categorizing students into preferred learning styles helps to link these styles to quality outcomes. To sum up, the cognitive aspect of learning of a learner profile should include the attributes of reflective and critical thinkers and knowledgeable learners.

The conative aspect examined by Bullock (2011), looks at personal intention and self-efficacy, and "explores the meta-cognitive notions of responsibility for, and awareness of, one's own learning" (p.2). The conation is described as "the drive that determines the nature and extent of involvement in a task" (ibid.). Drive is a form of motivation. Motivation, according to Ryan and Deci (2000), is not a single construct but a highly complex and multi-faceted thrust or drive. In Bruner's view (1996), autonomous learning is possible from the effort of discovering or experiencing and adapting concepts. He uses the term "scaffolding" to describe the structured assistance that more informed individuals give to learners to encourage them to develop new skills, attitudes or understanding. Thus, the conative aspect of the learner profile should contain the attributes of learners being an inquirer, exhibiting integrity, honesty and owning responsibilities of their learning.

The importance of the affective domain of learning was recognized in Bloom (1956), and later gained much attention of the educational researchers. Pintrich and Schunk (1996) argue that people's expectation for success is one of the most important predictors of achievement. According to Bandura's (1997) self-efficiency theory, a high self-perception of capability leads to high levels of effort and persistence and ultimately to high levels of achievement. Fouzder and Markwick (2000) suggest that students who see success as being within their control are more likely to adopt appropriate learning strategies. Thus, the important attributes of the affective domain in a learner profile advocates caring, risk-taking and being balanced.

Studies focusing on learner profile show that knowing about individual students does have a measurable positive impact on achievement (York, 2014). Teachers require the knowledge of the unique skills that every child brings to the classroom in order to target instruction towards students' needs - a pedagogical approach with strong empirical support (Connor, Morrison, Fishman, Schattschneider \& Underwood, 2007; O’Connor, Dearing \& Collins, 2011). A learner profile is a documentation about an individual student. Its purpose is to get a complete picture of the individual's current status or development and to take measures for the future development of the learner. Learner profiles may incorporate data such as learner's skills, strengths, interests and passions, likes and dislikes, potential barriers to learning, attitude to learning and so on. The profile can also describe a learner's needs, wants, plans and goals.

Learner profiles can be used to construct viable connections, create comprehensive and inclusive classrooms, build effective relationships, and understand technological differentiations or adaptations that may be needed for individual students. A teacher can also get to know its effectiveness in guiding instruction. Learner profiles encourage student ownership and motivates students to learn anywhere and at any time. It also reminds students of their understanding of the expected learning outcomes and their achievement of these outcomes. In the entire process of teaching and learning, it gives directions to teachers and policy makers to make changes if required. In short, it applies to all- student, teacher, parent or administrator, for continual learning. Research states that the Learner Profiles are worthy of study because of its central place in the overall curriculum (Poole, 2017). Further, Kelly Edmonds (n.d.) is of the opinion that it is important to have learners' profiles in order to design courses that best suit them. A complete picture of student's learning preferences and challenges can be reflected in the learner profile and, according to Carol Ann Tomlinson (2017), it can be shaped by the categories of learning styles, preferences, culture and gender.

While developing a learner profile, the attributes of the profile are first to be considered. The attributes showcase the values inherent to education - providing a long-term vision of education. Thus, it is a set of ideals that can inspire, motivate and focus the work of learners and teachers, uniting them in a common purpose (IB learner booklet,2006).

The first attribute to be considered is a 'balanced learner'. Being honest, having a good character with integrity are the foundation stones for a balanced success of a learner. The second is caring for others, society and the nation. The 
commitment to caring leads to making a positive difference in the lives of other learners and the nation at large. Being a good communicator is the third attribute which confirms the levels of confidence and clarity a learner has. Being an inquirer makes a learner to think and nurture his/her curiosity to develop further in reaching his/her goals. A learner needs to explore knowledge across a range of disciplines to engage with issues that have local and global relevance. So, a learner should be knowledgeable and open minded to seek and evaluate different points of view of different people. Without reflection, a learner goes blindly in his/her way of thinking and learning.

Being a reflective learner promotes academic success. If a student lives by his/her principles, he/she can create the world he/she lives in. A learner, therefore, should maintain his integrity by being principled.

Learners must be ready to take risks, if they want to move and grow from the known to the unknown. Critical and creative thinking are the important attributes of a learner profile. These attributes cannot be developed in isolation. These are intertwined with other factors in preparing students to meet the changing scenario and the changing demands of the society. The development of these attributes mainly depends on the curriculum, instruction, teachers and institutional support. Opportunities need to be provided in the curriculum and its implementation depends on the nature and the flexibility of the curriculum. The success of the instruction is hidden in teachers' qualifications, their effectiveness in embracing changes, understanding students' needs and styles of learning. Institutional support is a major factor in the delivery of instruction. All these factors put together result in effective implementation of the curriculum.

\section{THE STUDY}

This part of the paper discusses and explains the primary findings of the effectiveness of the learner profile in the successful implementation of the foundation program English language courses offered by the Centre for Preparatory Studies of Sultan Qaboos University in Oman,

The foundation program at the Centre for Preparatory Studies of Sultan Qaboos University has a long history of development, utilizing the expertise of many professionals, and is guided by several documents. One of these documents is the standards prescribed in the Oman Academic Accreditation Authority (OAAA) Standards document. The foundation program English language curriculum, which was initially implemented at Sultan Qaboos University in 2010, is now part of a larger unified foundation program curriculum, which consists of four components covering the areas of the English language, mathematics, computer skills, and study skills.

The foundation program courses are based on the learning outcomes which state the skills and strategies the students are expected to use upon completing each course in the corresponding areas. The outline document of each course includes the objectives of the Centre and the mapped learning outcomes. In addition, it also aligns with the university's objectives and graduate attributes. The course outline also includes course information such as assessment matrix, materials, pacing schedules and any other information deemed important to students.

To find out the effectiveness of the learning outcomes, several modes of gathering information are followed including included formative and summative assessment scores, completion of students' 'can do' lists, and student participation in various extracurricular activities. Having such facilities for learning in place, it is still important to find out the factors that are contributing to the successful implementation of the foundation program. Therefore, this study emerged out of this eagerness to explore more into the role of the situational factors in the implementation of the foundation program to successfully prepare students to meet the challenges of the 21 st century. While exploring the contextual factors responsible for the effective implementation of the program, the authors noticed the role of learner profile and its centrality in implementing the curriculum. One of the important areas in the on-going study is students' preconceptions, views and perceptions of the foundation program.

\section{A. Methodology}

To explore in detail foundation program learner profile and students' views on their learning experiences, a bilingual questionnaire in English and Arabic was developed, and the ethical approval was obtained from the Center's Research Committee. The data in the questionnaire were put under three sections. Student profile and background, including gender, age, and region in Oman, constituted section one, student understanding of the general education principles formed section two and the knowledge and skills students gained from the foundation program constituted the third section. The second and the third sections of the questionnaire focused on students' understanding of such core principles of general education, as communication skills, quantitative reasoning, computer literacy and critical thinking skills, and sought students' responses on their experiences of practicing these skills in the foundation program English language courses. The questionnaire was posted online and made available to students of the exit level courses in the foundation program at the Centre for Preparatory Studies of Sultan Qaboos University.

\section{B. Participants}

In total, 301 foundation program students of Sultan Qaboos University participated in the study. Data revealed that that there were differences in terms of age, school education and the regions in Oman from where students came from. These features of the learner profile were important and needed investigation to decide their effectiveness in the success of the foundation program. 
Out of all study participants, $84.3 \%$ were in the age group of 18 to 19 years, $8 \%$ were 17 years of age, one student was 16 years old and students who were 20 years and above constituted $7.3 \%$ of the sample. Regarding gender frequency, $162(53.8 \%)$ were males and remaining $139(46.2 \%)$ were female students, making males marginally more than female students. Almost all students $(98 \%)$ attended public schools in all governorates of Oman before joining the university. Only 6 students $(2 \%)$ received school education from private schools in Oman before coming to the university These 301 students represented 10 governorates of Oman. The highest number of the students who participated in the study were from Al Dakhiliayah region (79 participants) followed by the Muscat region (56 participants). Next came Al Batinah North (40 participants) and Al Batinah South (37 participants) respectively. Al Sharqiyah North was represented by 33 students and Al Sharqiyah South by 18 students. Twenty-seven students represented Al Dhahira region. Al Buraimi (6 students), AL Wusta (3 students) and the governorate of Musandam (2 students) were least represented.

\section{Results and Discussion}

The findings related to students' understanding of the general education principles cover their communication skills, critical thinking, computer literacy and quantitative reasoning skills.

Most of the participants $(90 \%)$ understood the importance of communication in the 21 st century. Only $4 \%$ of the participants responded they were not sure of the importance of communication. Others (6\%) said it was not required. On the statement, how communication skills helped students in their other subjects and studies, $85 \%$ responded very positively saying that it did help them in their studies. Nearly $50 \%$ of the respondents also said that teachers encouraged communication in the classroom.

All students responded to the 5 questions on critical thinking. Nearly half of the students (48.2\%) knew the meaning of the term 'critical thinking'. However, most of them were not sure of some aspects, including the concept of critical thinking (40.9\%), whether it was important for them to study and acquire critical thinking skills in the English language foundation program courses $(57.6 \%)$, and whether their teachers were encouraging them to develop critical thinking skills $(66.1 \%)$. Also, $41 \%$ of the students were not sure whether critical thinking helped them in their study.

The majority of the participants (71.8\%) responded positively to the term 'computer literacy'. According to them, computer literacy was important for students in the foundation program courses. $74 \%$ of the students said that being computer literate was helpful for their studies. However, $41.2 \%$ responded that they were not sure whether teachers encouraged the use of computers for language learning. The reason could be that certain components of language learning are best learnt through discussions and practice in class.

More than half of the students who participated in the study $(55 \%)$ said they were not sure of the meaning of the term 'quantitative reasoning'. Nearly half of the students $(50.9 \%)$ said that it was not necessary for the students in the foundation program courses to know about quantitative reasoning. Surprisingly, $64.5 \%$ of the respondents said that they were not sure whether teachers encouraged quantitative reasoning in their classes. $43.2 \%$ of the students were not sure whether quantitative reasoning would help them to study.

As for writing, most of the students $(51.8 \%)$ were not sure whether they could write logically, using strategies of drafting, revising, editing and so on. They were also not sure whether they could write for specific audience, identify relationships between textual and graphical information. Regarding using variety of structures in their writing, nearly half of the students $(60.1 \%)$ ) said they were unable to use or were not sure of using different structures in their writing and evaluating and synthesizing information from multiple sources without plagiarizing. About writing a thesis statement or developing the main idea, $61.4 \%$ students said they could not or were not sure of writing correctly the thesis or the main ideas.

Many students (32.9\%) were not sure of using standard English vocabulary. Half of the students (45.8\%) said they were able to identify arguments for and against a certain issue in a text. However nearly half of them (45.2\%) said they were unable to or were not sure of identifying for and against ideas for a certain issue in a text and argue convincingly. While presenting information, 51.2\% students expressed their ability to use visual aids effectively, while the others said they were not able to /or were not sure of using visual aids effectively.

Regarding knowledge and skills in using quantitative reasoning, half of the students $(63.4 \%)$ said they understood the concepts and they could apply the skills learnt in different contexts while $43.6 \%$ expressed their inability to understand /were not able to or not sure of applying skills to real world tasks. Students responded in a similar way to this skill as they responded to statements on quantitative reasoning. $61.8 \%$ of the students understood the relationships of key components, networks, data storage and software programs. Only $40 \%$ of the students were able to store and retrieve data from within the computer and or via network virtual drive. Though $23.9 \%$ of the respondents were not sure of effectively organizing, managing and presenting data using computer applications, 51.5\% were able to use computer applications effectively.

The areas which require critical thinking were justifying an opinion, constructing and asking questions, identifying main and supporting ideas, considering other's opinions and effectively managing their time. $62.5 \%$ of respondents were able to justify an opinion, $58.1 \%$ were able to construct and ask questions, $68.5 \%$ were able to identify main ideas and write supporting details. $49.8 \%$ responded positively for considering other people's opinion, and $48 \%$ said they were able to manage their time effectively. 
The findings of the study demonstrate that the concept of communication, both written and spoken, is clear to most of the students, though lack of vocabulary hinders their communication. This area - lack of vocabulary- is also reflected in their writing skills. Some students do not recognize the encouraging tasks used in class to promote communication, and most of them believe that foundation program students need to know about communication, and communication skills are important to them in their study. The concept of critical thinking is understood by the majority of the respondents but, according to them, they are not always able to think critically and apply these skills appropriately in real world tasks. Like the communication tasks in the class, students are not always able to recognize the encouraging efforts of their teachers in developing their critical thinking skills. Computer literacy is understood by the students as a concept but application of different programs is limited. This is also reflected in their writing and presentation tasks. The concept of quantitative reasoning is not clearly understood by majority of the students. This is possibly the reason of why the importance of acquiring quantitative reasoning skills is not clear to many students and they fail to identify the encouragement given by teachers to develop reasoning to promote mathematical skills. According to students, there is a lack of application of quantitative reasoning in their foundation program courses. This is reflected in their responses stating that when students make presentations, they are not always able to support their views using graphs, tables and charts in which percentages, numbers, decimals and ratios are used.

Overall, though the general education principles which are required in the 21 st century are well understood by the foundation program students, they need more venues for application of these principles. Also, the area of critical thinking needs more attention in the curriculum as well as in the delivery of instruction. As for the learner profile attributes, the student's responses show some missing areas related to critical thinking skills, self-directed learning, digital and media literacy, and taking initiatives. This situation can be improved by fine tuning the learning outcomes. As an additional help to comprehend the expected outcomes, the learning outcomes can be redrafted as 'Can-do' statements which will make it easy for learners to assess their own progress. For example, critical thinking attribute of the learner profile (learning outcome: will be able to argue in favor of an issue and convince others) can correspond to a can-do statement "I can speak confidently and argue and express my ideas clearly." Such initiative if implemented properly can result in student's better academic adjustment and development. However, a word of caution needs to be added. Achieving these skills and meeting the attributes cannot be done in one or two semesters; it is a long learning process. Students therefore need to be initiated into it as early as possible and the learning to continue until they graduate. Also, it is important for the English language foundation program curriculum to incorporate activities and challenging tasks based on the areas discussed because it is necessary to provide opportunities for the students to acquire and apply the acquired skills to real tasks at hand. The expected objectives of learning English should be comprehensible to the students. Teaching methodologies should match the learner profiles to meet the 21 st century requirements and various approaches to teaching/learning like, skills-centered, project-based, problem-based, taskbased and team-based should be used to ensure maximum student engagement.

\section{CONCLUSION}

By analyzing the learner profile attributes, it is much easier to identify the factors responsible for the success of any teaching program, and the foundation program at tertiary education institutions in Oman is not an exception. The learner profile has an important role in shaping the personality of Omani foundation program students and equipping them with all necessary skills required for their future academic studies and work. It may function as a guide for redesigning the foundation program curriculum, rethinking teaching methodologies and rewording the graduate attributes aligning with the societal demand. Learning outcomes can thus be written based on the expected attributes and then writing the 'cando' statements.

\section{ACKNOWLEDGMENTS}

The authors would like to extend their sincere appreciation and gratitude to the Deanship of Research at Sultan Qaboos University for supporting this study by an internal research grant.

\section{REFERENCES}

[1] Ausubel, D. \& F. Robinson. (1969). School learning: An introduction to educational psychology. London, UK: Holt, Rinehart and Winston.

[2] Bandura, A. (1997). Self-efficacy: The exercise of control. New York, USA. Freeman.

[3] Bar-Yam, M., Rhoades, K., Booth Sweeney, L., Kaput, J. \& Bar-Yam, Y. (2002). Complex systems perspectives on education and the education System, New England Complex Systems Institute. Retrieved June 1, 2019 from https://necsi.edu/changes-inthe-teaching-and-learning-process-in-a-complex-education-system.

[4] Bloom, B.S. (1956). Taxonomy of educational objectives, Handbook: The cognitive domain. David McKay, New York.

[5] Boud, D., Cohen, R. \& D. Walker (eds). (1993). Using experience for learning. Buckingham: The Society for Research into Higher Education and Open University Press.

[6] Bruner, J. (1996). The Culture of Education. Cambridge, MA. Harvard University Press.

[7] Bullock, K. (2011). International baccalaureate learner profile: Literature review. Retrieved May 30,2019 from https://www.ibo.org/globalassets/publications/ib-research/iblearnerprofileeng.pdf. 
[8] Connor, C. M., Morrison, F. J., Fishman, B. J., Schattschneider, C., \& P. Underwood. (2007). The early years: Algorithmguided individualized reading instruction. Science, 315, 464-465.

[9] Edmonds, K. (n.d.). What is a learner profile and why have one? Retrieved May 16, 2019 from https://drkellyedmonds.com/what-is-online-learner-profile/.

[10] Eisner, E. (2000). "Benjamin Bloom 1913-1999", Prospects: The quarterly review of comparative education. Paris, UNESCO: $\begin{array}{llllll}\text { International } \quad \text { Bureau } & \text { of } & \text { Education. } & \text { Retrieved }\end{array}$ teachpsych.org/resources/documents/conferences/bp/2013/Nevid\%20session.ppt.

[11] Fouzder, N. \& A. Markwick. (2000). Self-perception, individual learning style and academic achievement by a pair of bilingual twins in secondary school. International Journal of Science Education, 22(6), 583-601.

[12] Heffler, B. 2001. "Individual learning style and the learning style inventory". Educational Studies. 27(3), 307-316.

[13] IB learner booklet. (2006). Retrieved May 3, 2019 from http://www.quantum.am/en/IB_DP/files/The\%20Learner\%20Profile.

[14] O'Connor, E., Dearing, E. \& Collins, B.A. (2011). Teacher-child relationship and behavior problem trajectories in elementary school. American Educational Research Journal. 48(1), 120-162. Retrieved May 20, 2019 from https://necsi.edu/changes-inthe-teaching-and-learning-process-in-a-complex-education-system.

[15] Poole, A. (2017). Interpreting and implementing the IB Learner Profile in an internationalized school in China: a shift of focus from the 'Profile as text' to the 'lived Profile'. Journal of Research in International Education. 16(3), 248-264. Retrieved May 28 , 2019 from: https://www.researchgate.net/publication/321275269_Interpreting_and_implementingthe_IB_Learner_Profile_in_an_internatio nalised_school_in_China_a_shift_of_focus_from_the_'Profile_as_text'_to_the_'lived_Profile'.

[16] Pintrich, P. \& D. Schunk. (1996). The role of expectancy and self-efficacy beliefs. Englewood Cliffs, USA: Prentice-Hall.

[17] Ryan, R. E. Deci, E. (2000). Self-Determination theory and the facilitation of intrinsic motivation, social development, and well-Being. American Psychologist. 55(1), 68-78.

[18] Schön, D. (1991). The reflective practitioner: How professionals think in action. Alder shot, UK: Ashgate.

[19] Tomlinson, C.A. (2017). How to differentiate instruction in academically diverse classrooms, 3rd Edition. Alexandria, Virgini a: Association for Supervision and Curriculum Development (ASCD).

[20] Waterman, A.S. (1997). Service learning: Applications from research. New Jersey: Lawrence Erlbaum Associates.

[21] York, Benjamin, N. (2014). Know the child: The importance of teacher knowledge of individual students' skills (KISS). CA: Stanford University.

Meenalochana Inguva has received her $\mathrm{PhD}$ in language teaching and teacher education from the Central Institute of English and foreign Languages, Hyderabad, India. She has more than 30 years of teaching and teacher training experience across various levels. Currently she is on the faculty at the Centre for Preparatory Studies of Sultan Qaboos University in Oman, which she joined in 2000. During her time at the Centre she has been involved in curriculum design and development for the foundation program courses. Dr. Meenalochana Inguva worked as the Centre's Head of the Curriculum Unit for 3 years and then became the Standing Member of the Central Curriculum Committee. She has conducted several workshops for teachers of English. Her research interests focus on and include class-room based research, inter-cultural communication and evidence-based teaching.

Victoria Tuzlukova obtained her PhD in Applied Linguistics from Pyatigorsk University of Foreign Languages in Russia. She has also held a PhD in Comparative Linguistics from Moscow State University since 2002. She has over 30 years teaching and research experience in Russia and Oman. Currently she is on the faculty at the Centre for Preparatory Studies of Sultan Qaboos University in Oman, which she joined in 2006. During her time at the Centre she has been involved in a number of research projects and initiatives. Her research interests focus on sociolinguistics, intercultural communication, foreign language acquisition and the role of culture in foreign language teaching and learning. Dr. Victoria Tuzlukova has presented and published in a broad variety of international conferences and journals.

Pooja Sancheti has obtained her Master's degree in English Language and Literature from Himachal Pradesh University in India and has just submitted her M. Phil thesis. She has a collective experience of more than twenty years in teaching English to young adults and training middle school teachers. Currently, she is the Deputy Director for Professional Development and Research at the Centre for Preparatory Studies at Sultan Qaboos University in Oman. Pooja Sancheti has participated in and initiated several material development and review projects. She has presented her ideas through paper presentations and workshops at many international conferences concerning skills development. Pooja's research interests include EFL teaching and testing approaches and using critical thinking skills to enhance language acquisition. She believes that thinking critically is the key to learning, and education is all about pursuit of knowledge. 